\title{
Estradiol interacts with an opioidergic network to achieve rapid modulation of a vocal pattern generator
}

\author{
Luke Remage-Healey $•$ Andrew H. Bass
}

Received: 14 July 2009 / Revised: 7 December 2009 / Accepted: 8 December 2009 / Published online: 25 December 2009

(C) The Author(s) 2009. This article is published with open access at Springerlink.com

\begin{abstract}
Estrogens rapidly regulate neuronal activity within seconds-to-minutes, yet it is unclear how estrogens interact with neural circuits to rapidly coordinate behavior. This study examines whether 17-beta-estradiol interacts with an opioidergic network to achieve rapid modulation of a vocal control circuit. Adult plainfin midshipman fish emit vocalizations that mainly differ in duration, and rhythmic activity of a hindbrain-spinal vocal pattern generator (VPG) directly establishes the temporal features of midshipman vocalizations. VPG activity is therefore predictive of natural calls, and 'fictive calls' can be elicited by electrical microstimulation of the VPG. Prior studies show that intramuscular estradiol injection rapidly (within $5 \mathrm{~min}$ ) increases fictive call duration in midshipman. Here, we delivered opioid antagonists near the VPG prior to estradiol injection. Rapid estradiol actions on fictive calling were completely suppressed by the broad-spectrum opioid antagonist naloxone and the mu-opioid antagonist beta-funaltrexamine, but were unaffected by the kappa-opioid antagonist nor-binaltorphimine. Unexpectedly, prior to estradiol administration, all three opioid antagonists caused immediate, transient reductions in fictive call duration. Together, our results indicate that: (1) vocal activity is modulated by opioidergic
\end{abstract}

L. Remage-Healey · A. H. Bass

Department of Neurobiology and Behavior,

Cornell University, Ithaca, NY 14853, USA

e-mail: ahb3@cornell.edu

Present Address:

L. Remage-Healey ( $\square)$

Laboratory of Neuroendocrinology, Brain Research Institute, University of California, 621 Charles E. Young Dr., South,

P.O. Box 951606, Los Angeles, CA 90095-1606, USA

e-mail: healey@ucla.edu networks, confirming hypotheses from birds and mammals, and (2) the rapid actions of estradiol on vocal patterning depend on interactions with a mu-opioid modulatory network.

Keywords Nongenomic $\cdot$ Extranuclear $\cdot$ Membrane . Teleost $\cdot$ Opioid

\section{Introduction}

Estrogens rapidly regulate behavior within minutes in a variety of contexts, most notably the sexual behavior of male rats (Cross and Roselli 1999) and Japanese quail (Cornil et al. 2006b). Estrogens also act within seconds-tominutes on the neurophysiological properties of striatal, hippocampal and hypothalamic neurons (Qiu et al. 2003; Woolley 2007). These actions on neuronal excitability occur via interactions with ion channels and/or neurotransmitter receptors, including those for opioids (reviews: Kelly and Ronnekleiv 2002; Cornil et al. 2006a). Taken together, these observations suggest that the mechanisms established for estrogen action on neuronal activity mediate the rapid behavioral effects of estrogens. However, it remains largely unknown how estrogens rapidly modulate discrete networks of neurons that pattern behavioral output. In principle, estrogen-dependent modulation could be via either direct effects on central pattern generators or indirect effects on afferent modulatory networks.

$17-\beta$-Estradiol $\left(\mathrm{E}_{2}\right)$ modulates the activity of a vocal central pattern generator in a sound-producing teleost fish, the plainfin midshipman (Porichthys notatus) (RemageHealey and Bass 2004, 2007). Male midshipman establish and defend nests they build under rocky shelters, and emit long-duration ( $>1 \mathrm{~min}$ ) advertisement calls known as "hums" to attract females to their nests. Adults of both 
sexes emit short-duration ( $100 \mathrm{~ms})$ "grunts" during aggressive encounters (Brantley and Bass 1994; Bass and McKibben 2003). The rhythmic activity of hindbrain-spinal vocal pattern generator (VPG; see Fig. 1) directly establishes the fundamental frequency and duration of midshipman calls (Bass and Baker 1990). The output of the VPG ('fictive calls') can be evoked by excitation of midbrain and hindbrain sites (Bass and Baker 1990; Weeg et al. 2005; Kittelberger et al. 2006), and the temporal firing properties of the VPG directly establish the temporal features of natural calls (Bass and Baker 1990). Intramuscular $\mathrm{E}_{2}$ injection rapidly (within $5 \mathrm{~min}$ ) increases the duration of fictive calls in adult male and female midshipman (Remage-Healey and Bass 2004, 2007), and these effects are both short-lived (lasting 30-45 $\mathrm{min}$ ) and stereospecific. Androgens and glucocorticoids also cause rapid changes in fictive calling in this species and candidate receptor mechanisms have been identified by blocking these acute effects with cyproterone acetate (antiandrogen) and RU486 (antiglucocorticoid), respectively (Remage-Healey and Bass 2004). A similar candidate receptor mechanism has not yet been identified for the rapid effects of $E_{2}$. The rapid actions of $\mathrm{E}_{2}$ are localized to the hindbrain-spinal region that contains the VPG (Remage-Healey and Bass 2004), but whether $E_{2}$ acts directly on the VPG itself, or via indirect actions on neurons that modulate the VPG, is unknown. The midshipman model system therefore presents an opportunity to identify mechanism(s) of acute estrogen action on a defined neural circuit (shared by all major vertebrate lineages, see Bass et al. 2008) that patterns vocalizations.

Here, we test the hypothesis that an opioidergic network provides a modulatory mechanism for the rapid actions of $\mathrm{E}_{2}$ in midshipman. Our focus on opioidergic mechanisms is related to three previous observations. First, rapid $\mathrm{E}_{2}$ actions on mammalian hypothalamic neurons occur via interactions with opioidergic systems (Kelly et al. 1992; Qiu et al. 2003). Second, a membrane-bound receptor that is proposed to mediate rapid corticosteroid suppression of clasping behavior in amphibians exhibits opioid-like binding properties (Evans et al. 2000). Lastly, longer-term (i.e., hours to days) interactions between steroids (estrogens and progestins) and opioidergic neurons have emerged in studies examining the regulation of sexual receptivity in rodents (Eckersell et al. 1998; Sinchak and Micevych 2001; Acosta-Martinez and Etgen 2002). We report results for three opioid antagonists: naloxone, a broad-spectrum opioid blocker; beta-funaltrexamine, a blocker specific to mu-opioid neurons in other vertebrates; and nor-binaltorphimine, a blocker specific to kappa-opioid neurons in other vertebrates (Bodnar and Klein 2006). We note that the receptor specificity of these antagonists has not been fully characterized for opioid receptors in teleosts, but that opioid receptor subtypes are broadly conserved among vertebrates (Brooks et al. 1994; Ebbesson et al. 1996; Khalap et al. 2005, see discussion).

\section{Materials and methods}

Animals

Midshipman fish have two adult male morphs that diverge in a large suite of traits including reproductive tactics and vocal behaviors (Brantley and Bass 1994). Type I males build and guard nests in the intertidal zone, whereas smaller type II males sneak and satellite spawn in attempt to steal fertilizations from type I's. Only type I males are known to produce the long-duration advertisement hums as well as extended trains of brief agonistic grunts and growls that are intermediate in duration between hums and grunts (Bass and McKibben 2003). Type II males and females are only known to generate grunts in non-spawning contexts. This study included 40 type I males (13-20 cm standard length) collected from nest sites in northern California and Washington state. While females have the highest plasma $E_{2}$ levels, detectable levels of circulating $E_{2}$ are found in close to $70 \%$ of type I males during pre-nesting and nesting periods (Sisneros et al. 2004). Also, aromatase-containing glial cells surround the dorsolateral aspect of the vocal motor nucleus (VMN) and have processes that ramify throughout the $\mathrm{VMN}$ which likely provide a local source of $\mathrm{E}_{2}$ via aromatization of circulating testosterone (Forlano et al. 2001; Sisneros et al. 2004).

Evoked activity of the vocal pattern generator (VPG)

Electrophysiology procedures closely followed those outlined in earlier studies with midshipman fish (Bass and Baker 1990; Goodson and Bass 2000; Remage-Healey and Bass 2004). The brain and rostral spinal cord were exposed by dorsal craniotomy under general anesthesia $(0.025 \%$ benzocaine; Sigma) and long-lasting analgesia $(0.25 \%$ bupivacaine; Abbott Laboratories, Chicago, IL; with $0.01 \mathrm{mg} / \mathrm{mg}$ epinephrine; International Medication Systems, El Monte, CA). Following surgery, fish were stabilized in a plexiglass tank during recovery and perfused through the mouth with fresh saltwater maintained at $17^{\circ} \mathrm{C}$ with a Peltier device. Exposed brain areas were covered with Flouroinert $(3 \mathrm{M}$ Corp., St. Paul, MN), and intramuscular injections of pancuronium bromide $(0.5 \mathrm{mg} / \mathrm{kg}$; Astra Pharmaceutical Products, Westborough MA) were used for immobilization. Brief electrical stimuli (pulse width $=0.1 \mathrm{~ms}$, frequency $=$ $250 \mathrm{~Hz}$, duration $=25 \mathrm{~ms}$ ) were delivered via an insulated tungsten electrode exposed at the tip (Fig. 1b) to a hindbrain-spinal vocal site VPP (Bass et al. 2008), formerly 
a

experimental timeline

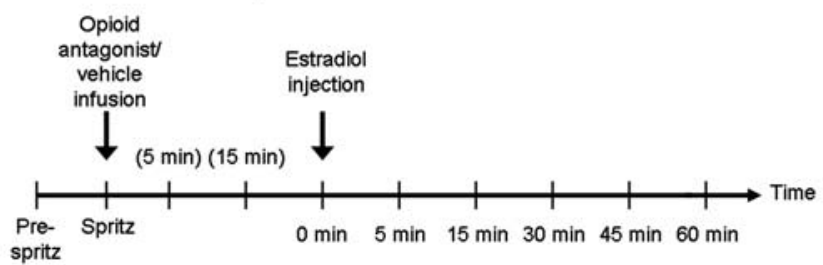

b

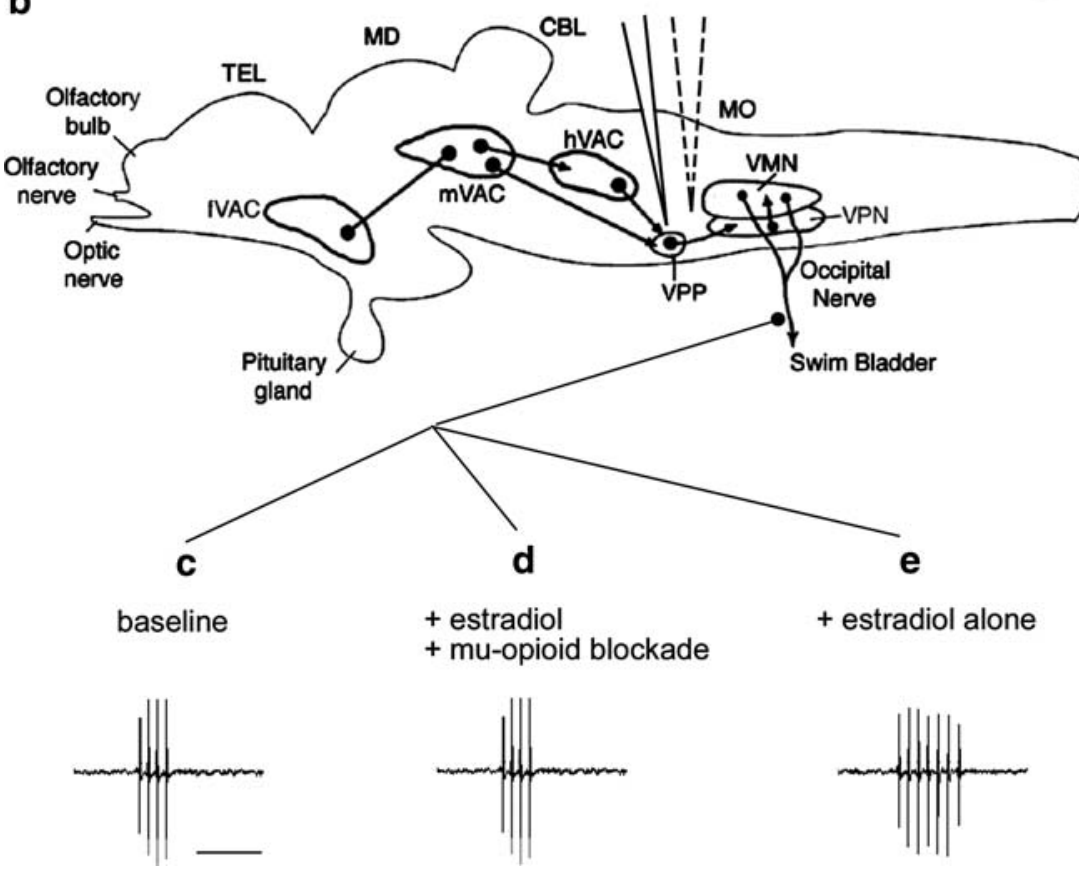

Fig. 1 a Schematic of the experimental timeline for opioid antagonist infusion ('spritz') followed by estradiol $\left(\mathrm{E}_{2}\right)$ injection, as indicated by vertical arrows. Each vertical line on the time axis represents an extracellular recording sample; parentheses indicate recording sample times during the post-spritz period. b Sagittal line drawing of the midshipman brain, showing the major nuclei in the descending vocal control system (Bass et al. 1994; Goodson and Bass 2002). The hindbrain-spinal vocal pattern generator $(V P G)$ consists of a vocal motor nucleus $(V M N)$ that innervates the vocal swimbladder muscles via occipital nerve roots, an adjacent column of vocal pacemaker neurons $(V P N)$ which temporally pattern the activity of the VMN, and a rostral vocal prepacemaker nucleus $(V P P)$. The VPG receives descending input from vocal-acoustic centers $(V A C)$ in the hindbrain $(h)$, midbrain $(m)$, and forebrain $(f)$. Electrical microstimulation of the VPP region

designated as VM (Bass et al. 1994), that is vocally active (Remage-Healey and Bass 2004; 2006). Electrically evoked vocal motor volleys were recorded with an extracellular electrode (Teflon-coated silver wire with exposed ball tip) placed on a ventral occipital nerve root that carries vocal motor axons to the ipsilateral vocal muscle attached to the lateral walls of the swim bladder (Fig. 1b). Activity recorded from either left- or right-side occipital nerve root reflects bilateral output (Bass and Baker 1990). Rhythmic vocal motor volleys occurred as discrete bursts (fictive calls, Fig. 1a-c) similar to natural grunts (see Brantley and Bass (solid electrode) elicits patterned fictive calls (traces below; illustrations only and not real data) recorded via extracellular electrode adjacent to the occipital nerve root. Also depicted is the drug delivery electrode (dashed electrode) within the fourth ventricle. $M O$ medulla oblongata, $C B L$ cerebellum, $M D$ midbrain, TEL telencephalon. c-e Illustrations of three modulatory effects on midshipman hindbrain-spinal VPG activity. Traces are $250 \mathrm{~ms}$ in duration (scale bar $100 \mathrm{~ms}$ ) and are depicted for illustration purposes only. c Functional mu- and/or kappa-opioid circuits within the VPG region are required for baseline fictive call duration. $\mathbf{d}$, $\mathbf{e}$ Rapid actions of $\mathrm{E}_{2}$ on fictive call duration require the presence of functional mu-opioidergic circuits. In the absence of functional mu-opioid circuits (d) fictive call duration remains at baseline. The combined rapid actions of $\mathrm{E}_{2}$ and mu-opioidergic circuits (e) result in increased fictive call duration

1994) and were recorded at 1-s intervals. Recordings were digitized on a Macintosh using IGOR Pro software (Wavemetrics, Inc., Lake Oswego, OR). The duration of each fictive call was measured from the recordings and the mean burst duration was computed for each time point and normalized to $100 \%$ of baseline output.

Delivery of opioid antagonists

All opioid antagonists were obtained from Tocris Bioscience (Ellisville, MO) and dissolved in buffered teleost 
Ringer's (Forster-Taggart) solution (all solutions had $\mathrm{pH}$ between 6.81 and 8.19 ). Fictive calls evoked from the hindbrain-spinal VPP region were considered stable when a single fictive call was entrained to each stimulus. Once stability was established, a series of ten fictive calls was evoked at 1-s intervals to determine baseline (pre-drug) vocal motor output. Immediately following the baseline period, either saline vehicle ( $n=4$ animals) or one of three opioid receptor antagonists was pressure injected (see below) into the hindbrain (fourth) ventricle that directly borders the VMN (see Fig. 1b) (Bass and Baker 1990; Bass et al. 1994). Antagonists included the broad-spectrum opioid receptor antagonist naloxone $(1,10,25 \mathrm{mM} ; n=6,4,4$ animals each, respectively), the mu-specific opioid antagonist beta-funaltrexamine $(1,10 \mathrm{mM} ; n=4$ each), and the kappa-specific opioid antagonist nor-binaltorphimine $(0.66$, $6.6 \mathrm{mM} ; n=3$ each). Drug doses were based on previous studies of opioid-steroid interactions (Evans et al. 2000; Acosta-Martinez and Etgen 2002; Ceccarelli et al. 2004; Schmitt and Kaufman 2005). The standard dose sequence $(1,10 \mathrm{mM})$ was lowered slightly for nor-binaltorphimine due to limited reagent availability; it is an effective kappaopioid antagonist in both mammalian and non-mammalian vertebrates (Bradford et al. 2005).

Drugs and vehicle were delivered via a glass micropipette (microfilament $60101.0 \mathrm{~mm}$ OD, AM Systems, Carlsborg, WA) with broken tips (18-20 $\mu \mathrm{m})$ using a picospritzer (Biomedical Engineering, Thornwood, NY). Only one dose of opioid antagonist or vehicle was used per experiment (i.e., in each animal). Injection parameters followed those well-established for this preparation (one pressure pulse per second at $30 \mathrm{psi}$ and pulse duration of $10 \mathrm{~ms}$ for estimated infusion volume of approximately $0.16 \mathrm{nl}$; see Goodson and Bass 2000; Kittelberger et al. 2006). The picospritzer electrode was checked before and immediately following each experiment to verify that pressure delivery was functional. A simultaneous recording of ten fictive calls was obtained (as above) concurrent with pressure delivery of solutions to identify any instantaneous effects of either drug or saline delivery on vocal motor patterning (see also the experiment timeline in Fig. 1a). Two subsequent recordings of 15 fictive calls were obtained at 5 and $15 \mathrm{~min}$ following solution delivery (all treatments prior to $\mathrm{E}_{2}$ administration; see Fig. 1a) to determine whether drugs or saline altered vocal motor patterning. Five minutes after the 15 -min post-drug recording, fish were administered an intramuscular injection (dorsal trunk muscle) of $E_{2}(0.02 \mathrm{mg} / \mathrm{kg})$ via a pre-inserted $23-\mathrm{G}$ butterfly needle. This treatment dose rapidly increases fictive call duration (within $5 \mathrm{~min}$ and lasting up to $30 \mathrm{~min}$ ) in type I male midshipman (Remage-Healey and Bass 2004, 2007). Immediately following the injection, a subsequent series of 15 fictive calls were obtained at $5,15,30,45$, and $60 \mathrm{~min}$, and each time point was standardized to $100 \%$ of the baseline output. After the last recording, blood samples were obtained from the gill arch (Remage-Healey and Bass 2004, 2005; Remage-Healey and Bass 2006), and plasma was analyzed for $\mathrm{E}_{2}$ using enzyme immunoassay (Cayman Chemical, Ann Arbor, MI, techniques reported previously in Remage-Healey and Bass 2004, 2005, 2007). Plasma $E_{2}$ levels were confirmed to be elevated (mean $=34.52$ $\mathrm{ng} / \mathrm{ml} \pm 8.01 \mathrm{SEM} ; n=16$ ) for a subset of animals that received $E_{2}$ injections (see also Remage-Healey and Bass 2004).

Analysis

As described above, fictive call durations were sampled and standardized to $100 \%$ of baseline. Statistical analyses of the effects of drugs on fictive call duration were performed using Statview 4.57. Repeated-measures ANOVA was performed for data from all treatments for analysis of treatment effects over time in a within- and between-subjects design. Tukey's post hoc tests are reported for betweensubject effects for comparisons of saline versus drug treatments for $P<0.05$.

\section{Results}

\section{Overview}

We first show that each of the opioid antagonists used herenaloxone, beta-funaltrexamine, and nor-binaltorphiminecaused a rapid and brief (either immediate or within $5 \mathrm{~min}$ of infusion) suppression of fictive calling when delivered to the hindbrain VPP region. All antagonists had similarly brief effects when initially applied, but calling recovered to baseline quickly (within 5-10 min). In contrast, subsequent attenuation of rapid $E_{2}$ effects on fictive calling was both antagonist-specific and prolonged, lasting up to 30-60 min. This encompasses the duration of $\mathrm{E}_{2}$ 's actions on fictive calling in this species (Remage-Healey and Bass 2004, 2007). Only naloxone and the mu-opioid-specific antagonist betafunaltrexamine, but not the kappa-opioid antagonist nor-binaltorphimine, inhibited $\mathrm{E}_{2}$ 's effects on calling.

Antagonists alone

\section{Naloxone}

The broad-spectrum opioid antagonist naloxone $(1,10$, and $25 \mathrm{mM}$ ) caused a transient reduction in fictive call duration, in a dose-dependent manner (Fig. 2a). There were significant effects of time-after-delivery $(F=8.74 ; d f=3,42$; $P=0.0001)$, a dose $\times$ time interaction $(F=3.36 ; d f=9.42$; $P=0.003$ ), and a non-significant trend for the effect of dose 

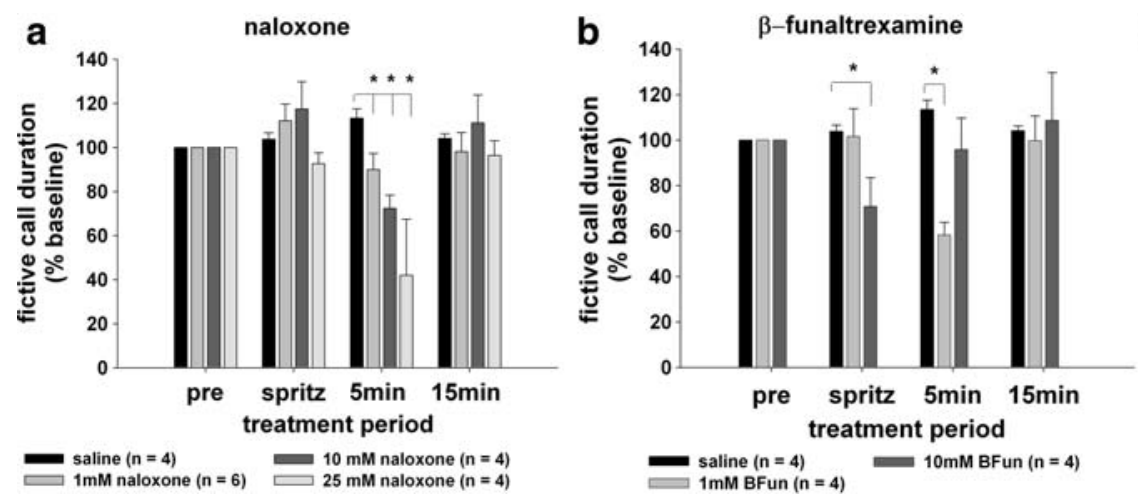

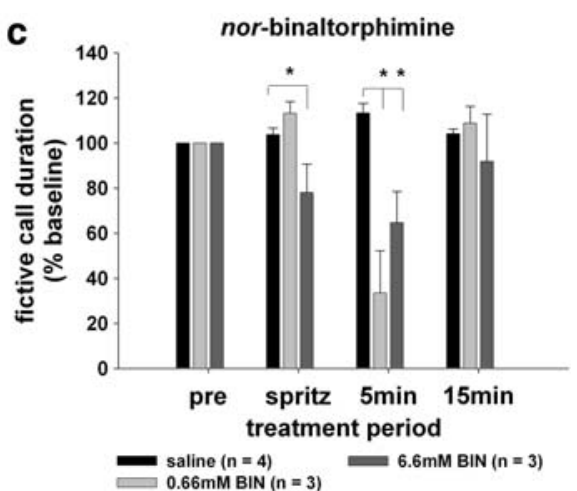

Fig. 2 Interocerebroventricular microinjection of opioid antagonists rapidly reduce fictive call duration in midshipman. The broad-spectrum opioid antagonist naloxone (a) the mu-specific-opioid antagonist beta-funaltrexamine (b) and the kappa-specific-opioid antagonist nor- binaltorphimine (c) each transiently suppress fictive call duration. All treatment effects recover to baseline at $15 \mathrm{~min} . * P<0.05$ for Tukey's post hoc test for between-subject comparisons of fictive calling during infusion of antagonists versus vehicle (saline)
$(F=3.12 ; \quad d f=3,14 ; \quad P=0.06)$. Tukey's post hoc test revealed that naloxone produced significant $(P<0.05)$ reductions in fictive call duration at $5 \mathrm{~min}$ after delivery for all three doses $(1,10,25 \mathrm{mM})$ when compared to saline alone. Fictive call duration was indistinguishable from baseline at $15 \mathrm{~min}$ following naloxone treatment. For the 5-min time point, the response to naloxone was linearly dose-dependent; i.e., there was a larger reduction in fictive call duration as the doses of naloxone increased.

\section{Beta-funaltrexamine}

The mu-specific opioid antagonist beta-funaltrexamine (1, $10 \mathrm{mM}$ ) also caused a transient reduction in fictive call duration (Fig. 2b). There were significant effects of timeafter-delivery $(F=3.69 ; d f=3.27 ; P=0.04)$, a dose $\times$ time interaction $(F=5.55 ; d f=6.27 ; P=0.0007)$, and no significant effect of dose $(F=1.21 ; d f=2.9 ; P=0.34)$. Tukey's post hoc test revealed that beta-funaltrexamine produced significant $(P<0.05)$ reductions in fictive call duration immediately upon delivery ('spritz'; $10 \mathrm{mM}$ dose) and at $5 \mathrm{~min}$ after delivery ( $1 \mathrm{mM}$ dose) when compared to saline alone. While the time-dependence of the response to beta-funaltrexamine differed slightly for the two doses, they were similar in temporal pattern. That is, the larger dose $(10 \mathrm{mM})$ produced only an immediate reduction in fictive calling and the lower dose $(1 \mathrm{mM})$ produced a reduction only at $5 \mathrm{~min}$ after delivery of the drug; each recovered to baseline by the next time point tested, i.e., within at least $5 \mathrm{~min}(10 \mathrm{mM})$ or $10 \min (1 \mathrm{mM})$. Fictive call duration was indistinguishable from baseline at 15 min following beta-funaltrexamine treatment.

\section{Nor-binaltorphimine}

The kappa-specific opioid antagonist nor-binaltorphimine $(0.66,6.6 \mathrm{mM})$ also caused a transient reduction in fictive call duration that was, like naloxone, dose-dependent (Fig. 2c). There were significant effects of time-after-delivery $(F=11.43 ; d f=3.21 ; P=0.0001)$, a dose $\times$ time interaction $(F=11.91 ; d f=6.21 ; P<0.0001)$, and a significant effect of dose $(F=29.7 ; d f=2.7 ; P=0.0004)$. Tukey's post hoc test revealed that nor-binaltorphimine produced significant $(P<0.05)$ reductions in fictive call duration immediately upon delivery ( $0 \mathrm{~min} ; 6.6 \mathrm{mM}$ dose $)$ and at $5 \mathrm{~min}$ after delivery ( 0.66 and $6.6 \mathrm{mM}$ doses) when compared to saline alone. Fictive call duration was indistinguishable from baseline at $15 \mathrm{~min}$ following nor-binaltorphimine treatment. Similar to beta-funaltrexamine, the dose-dependence of the response to nor-binaltorphimine was apparent in that only the highest dose $(6.6 \mathrm{mM})$ produced an immediate reduction in fictive calling. Unlike beta-funaltrexamine, both low and high doses produced reductions in fictive calling at the 5-min time point. Similar to both naloxone and beta-funaltrexamine, fictive call suppression that was present at $5 \mathrm{~min}$ recovered to baseline at the next time point tested, i.e., $15 \mathrm{~min}$ after picospritzing the drug.

Antagonists together with $\mathrm{E}_{2}$

\section{Naloxone}

The broad-spectrum opioid antagonist naloxone $(1,10$, and $25 \mathrm{mM}$ ) caused suppression of $E_{2}$ 's rapid effects on fictive call duration that was dose-dependent (Fig. 3a). There were significant effects of time-after-injection $(F=2.43$; $d f=5.60 ; P=0.04)$, a dose $\times$ time interaction $(F=2.23$; $d f=15.60 ; P=0.01)$, and a significant effect of naloxone dose $(F=5.33 ; \quad d f=3.12 ; \quad P=0.01)$ when comparing naloxone $+\mathrm{E}_{2}$ treatments versus saline $+\mathrm{E}_{2}$ treatment. Tukey's post hoc test revealed that naloxone $+\mathrm{E}_{2}$ treatments produced significantly shorter fictive call duration from saline $+\mathrm{E}_{2}$ treatment at $5 \mathrm{~min}(10$ and $25 \mathrm{mM})$, 

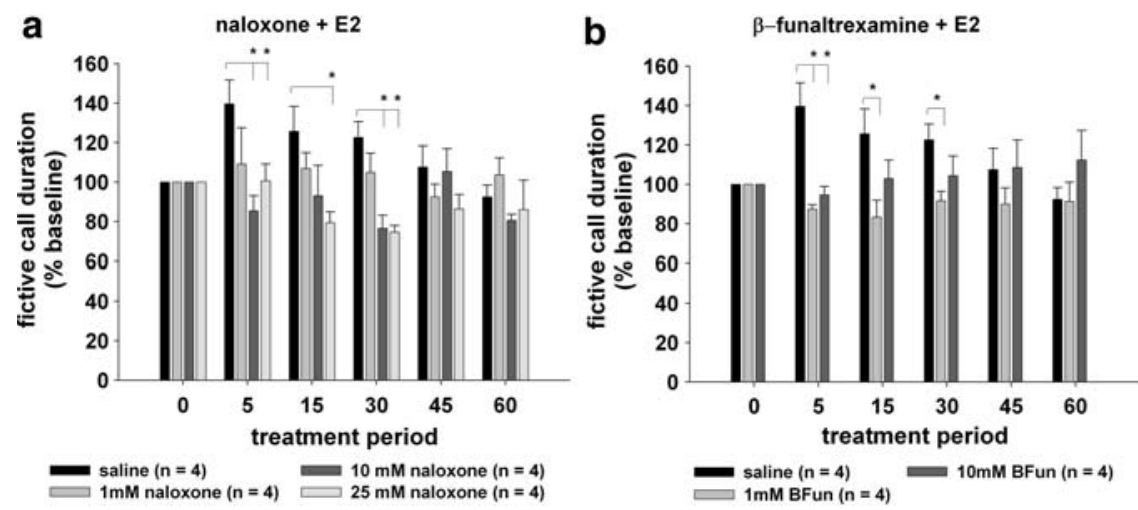

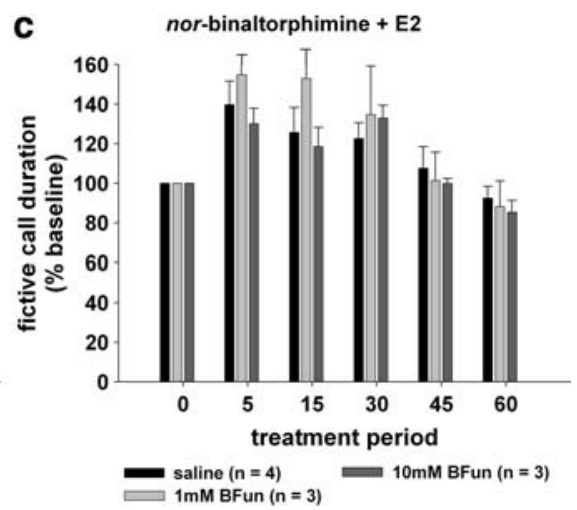

Fig. 3 Pre-treatment with mu-opioid antagonists suppresses the rapid actions of $17-\beta$-estradiol (E2) on fictive calling in midshipman. The broad-spectrum opioid antagonist naloxone (a) and the mu-opioid-specific antagonist beta-funaltrexamine (b) each significantly suppress the acute increase in fictive call duration following E2 injection at 5, 15

$15 \mathrm{~min}(25 \mathrm{mM})$, and $30 \mathrm{~min}(10$ and $25 \mathrm{mM})$. Therefore, only the intermediate $(10 \mathrm{mM})$ and high $(25 \mathrm{mM})$ doses of naloxone were effective in suppressing the rapid actions of E2.

\section{Beta-funaltrexamine}

The mu-specific opioid antagonist beta-funaltrexamine (1, $10 \mathrm{mM}$ ) also suppressed $\mathrm{E}_{2}$ 's rapid effects on fictive call duration (Fig. 3b). There was no significant effect of timeafter-injection $(F=0.68 ; d f=5.45 ; P=0.64)$, but there was a significant dose $\times$ time interaction $(F=3.44 ; d f=10.45$; $P=0.002)$ and a significant effect of beta-funaltrexamine dose $(F=4.26 ; d f=2.9 ; P=0.05)$ when comparing betafunaltrexamine $+\mathrm{E}_{2}$ treatments versus saline $+\mathrm{E}_{2}$ treatment. Like naloxone, Tukey's post hoc test revealed that beta-funaltrexamine $+\mathrm{E}_{2}$ treatments produced significantly shorter fictive call duration from saline $+\mathrm{E}_{2}$ treatment at $5 \mathrm{~min}(1 \mathrm{and} 10 \mathrm{mM}), 15 \mathrm{~min}(1 \mathrm{mM})$, and $30 \mathrm{~min}(1 \mathrm{mM})$. Thus, unlike naloxone, only the low $(1 \mathrm{mM})$ dose of betafunaltrexamine was effective in suppressing the entire timecourse of rapid $\mathrm{E}_{2}$ actions, while the response to the high $(10 \mathrm{mM})$ dose was no longer significantly different from the saline $+\mathrm{E}_{2}$ treatment after $15 \mathrm{~min}$.

\section{Nor-binaltorphimine}

Unlike naloxone and beta-funaltrexamine, the kappa-specific antagonist nor-binaltorphimine $(0.66,6.6 \mathrm{mM})$ had no significant effect on the rapid increase in fictive call duration induced by $\mathrm{E}_{2}$ (Fig. 3c). There was a significant effect of time-after-injection (response to $\mathrm{E}_{2} ; \quad F=10.70$; $d f=5.35 ; P<0.0001)$, but there was no time $\times$ dose interaction $(F=0.57 ; d f=10.35 ; P=0.83)$, and no significant effect of binaltorphimine dose $(F=0.42 ; d f=2.7 ; P=0.67)$ and $30 \mathrm{~min}$. In contrast, the kappa-opioid-specific antagonist nor-binaltorphimine (c) produces no effect on the rapid actions of E2, indicating that the observed actions are mu-opioid-specific. $* P<0.05$ for Tukey's post hoc test for between-subject comparisons of fictive calling during infusion of antagonists versus vehicle (saline)

when comparing nor-binaltorphimine $+\mathrm{E}_{2}$ treatments versus saline $+\mathrm{E}_{2}$ treatment. Tukey's post hoc test did not detect significant differences between nor-binaltorphimine $+\mathrm{E}_{2}$ and saline $+\mathrm{E}_{2}$ treatment for any time point at any dose. It is possible that a higher dose of nor-binaltorphimine would have caused suppression of fictive calling. However, the current dose regimen matched the order of magnitude for the other opioid antagonists used in this study (micro- to milli-molar range) and is within the high-range of doses for effective kappa-opioid blockade as reported in the literature (Gogas et al. 1996; Mitchell et al. 2005; Bodnar and Klein 2006; Pascoe et al. 2008).

\section{Discussion}

This study reports that intracerebroventricular microinjection of opioid antagonists can acutely inhibit fictive calling in midshipman fish. We also report that the rapid neuromodulation of fictive calling by $E_{2}$ is suppressed during specific inhibition of a central mu-opioidergic network. Our findings are therefore consistent with the hypothesis that rapid $\mathrm{E}_{2}$ actions on hindbrain-spinal VPG activity occur via interactions with a central mu-opioidergic network whose activation, in turn, modulates the VPG (as summarized in Fig. 1).

Opioidergic network and vocal mechanisms

This study provides evidence that opioids are neuromodulatory in contexts outside of their well-established role in regulating nociception and reinforcement/reward via actions in the forebrain (Bodnar and Klein 2006). The current observation that opioidergic neurons are involved in modulating vocal motor mechanisms may not be unique to midshipman 
fish, since opioids and their receptors are expressed throughout the song-control pathway in oscine (Deviche et al. 1993) and non-oscine (Durand et al. 1998) songbirds. Furthermore, opioids regulate vocal behaviors in both songbirds and mammals (Riters et al. 2005; Bodnar and Klein 2006), and, consistent with these earlier observations, the current study provides neurophysiological evidence that opioidergic neurons participate in the patterning of vocalizations.

Both the mu-specific (beta-funaltrexamine) and the kappa-specific (nor-binaltorphimine) opioid antagonists caused immediate suppression of fictive call duration during infusion ('spritz'; latency $<1 \mathrm{~min}$ ), whereas the broadspectrum opioid antagonist naloxone caused vocalization suppression after a latency of $5 \mathrm{~min}$. Therefore, suppression was common to all three antagonists as was a rapid recovery to baseline. Relative to the other antagonists, the naloxone effect was delayed but similarly short-lived, which may relate to differences in the ability of each drug to penetrate neural tissue due to chemical structure or potency (see also Martin et al. 2006; Chaijale et al. 2008). It is noteworthy that the binding affinity of opioid antagonists to mu- and kappa-opioid receptors have been well-characterized for mammals, but not yet for teleost fishes. A lack of strict dose-dependence for these opioid antagonist treatments on fictive calling makes non-specific effects of microinjection (such as concentration-dependent changes in $\mathrm{pH}$ or other interfering substances) unlikely. However, we cannot formally rule out the possibility of immediate and non-specific artifacts of microinjection on vocal motor network properties given that all of the antagonists, in general, suppress fictive call duration.

Opioid peptide and receptor expression in the midshipman central nervous system is currently un-described. Opioids and their receptors are highly conserved among vertebrates (Khalap et al. 2005), and neuroanatomical evidence for opioid networks exist for other teleost fishes (Brooks et al. 1994; Ebbesson et al. 1996). In coho salmon, mu-opioid binding sites are reported throughout the telencephalon, diencephalon and mesencephalon (Ebbesson et al. 1996), but the distribution of mu-opioid binding sites in the hindbrain are currently unknown in any teleost (delta-opioid receptors are found in the hindbrain of zebrafish, specifically in the periventricular zone and abutting the nucleus of the medial longitudinal fasciculus, Porteros et al. 1999). The indication that a mu-opioidergic network is critical for rapid actions of estrogens in midshipman fish is intriguing in light of the observation that brain mu-opioid systems are the most highly conserved among vertebrates (Li et al. 1996; Darlison et al. 1997).

Opioidergic neurons that modulate midshipman vocal patterning could have multiple neuroanatomical origins. One of the major descending opioid projections in verte- brates is the midbrain periaqueductal gray (PAG, Behbehani 1995), a critical node linking forebrain to hindbrain vocal neurons in midshipman fish (see Kittelberger et al. 2006, PAG is part of the mVAC in Fig 1 top) as well as in mammals (Jurgens 2008). The current findings are consistent with the hypothesis that descending opioidergic neurons from the PAG have terminals in the hindbrain-spinal VPG, and that their activity contributes to the rapid modulation of vocalizations in midshipman. This hypothesis predicts that a subset of the projections from the PAG to the VPG consist of opioidergic processes that are rapid modulated by estrogens (directly or indirectly, see below).

\section{Opioids and rapid estrogen mechanisms}

We report that mu-opioidergic antagonists block the rapid actions of $E_{2}$ during a 15-60 min period after microinjection into the hindbrain ventricle adjacent to the VPG. This indicates that opioid blockers exert long-lasting effects on the VPG comprised of mechanisms that could be substantially different from the immediate $(0-5 \mathrm{~min})$ inhibitory effects of opioid blockers on fictive calls. Opioid agonists and antagonists are known to have delayed (minutesto-hours) modulatory actions on network function (Brown et al. 1998), which consist of mechanisms distinct from rapid opioidergic (seconds-to-minutes) actions on neural activity (Heinricher 2003; Nugent et al. 2007). The current results suggest that similarly divergent acute versus delayed opioid mechanisms can each exert modulatory influences on the VPG circuit in midshipman.

One mechanism to account for the current findings is that opioid antagonists broadly suppress neuronal activity, including activity within the VPG, and that this suppression precludes the rapid actions of $E_{2}$ on the VPG. Consistent with this hypothesis, opioid agonists and antagonists exert long-lasting suppression of activity within neural circuits in a variety of contexts (Bennett and Mayer 1979; Cheng et al. 1986; Charpak et al. 1988). However, in the current experiments, the midshipman VPG recovered from suppression (i.e., returned to $100 \%$ of baseline fictive calling) within 5-10 min following treatment with all three opioid receptor antagonists. Secondly, mu-opioid blockade suppressed baseline VPG activity (Fig. 2b) and subsequent rapid $E_{2}$ actions (Fig. 3b), yet kappa-opioid blockade only rapidly suppressed VPG activity (Fig. 2c), but did not subsequently influence $E_{2}$ 's rapid actions (Fig. 3c). These findings together indicate that there are specific modulatory interactions between $\mathrm{E}_{2}$ and a candidate mu-opioidergic network in the midshipman VPG region.

The candidate cellular mechanism(s) for combined $\mathrm{E}_{2} /$ mu-opioid regulation of the VPG include either $\mathrm{E}_{2}$ binding directly to opioid receptors (Gutierrez et al. 1998), or to nonclassical binding sites on opioidergic neurons (Lagrange 
et al. 1997). These nonclassical actions of $E_{2}$ could occur either directly on modulatory mu-opioidergic neurons, or indirectly via an as yet unidentified modulatory input afferent to mu-opioidergic neurons. The acute nature of our findings indicate that the site of rapid $\mathrm{E}_{2}$ action within the VPG region is a nonclassical estrogen-binding site. Although the selective estrogen-receptor modulator ICI 182,780 potently blocks long-term estrogen-receptor mechanisms in other teleosts (e.g., Menuet et al. 2005; Pinto et al. 2006a, 2006b), pilot studies indicate that ICI is ineffective at modulating $\mathrm{E}_{2}$ 's rapid actions on vocal patterning in midshipman fish (Remage-Healey and Bass, unpublished observations). The binding site which mediates rapid $\mathrm{E}_{2}$ effects in midshipman may therefore be structurally dissimilar to the nuclear estrogen receptor (i.e., a membrane receptor/ion channel); alternatively, the rapid actions of $\mathrm{E}_{2}$ could be mediated by nonclassical mechanisms associated with the canonical cytosolic estrogen receptor(s) (e.g., Vasudevan et al. 2005). Previous evidence from rats indicates that $E_{2}$ increases the availability of mu-opioid receptors in hypothalamic inhibitory neurons (Torres-Reveron et al. 2009), suggesting that the rapid effects of $E_{2}$ observed here could be via similarly nonclassical interactions with hindbrain/spinal GABAergic neurons that are mu-opioid responsive. Although more neuroanatomical evidence is needed for teleosts, $E_{2}$ can modulate opioidergic function in the brainstem of rats (Tashiro et al. 2008) and opioid receptor mRNA is co-localized with estrogen-receptor positive cells in brainstem circuits (Flores et al. 2003).

The rapid $\mathrm{E}_{2} /$ opioidergic modulation reported here is a part of a growing number of reports indicating that steroids interact with opioidergic systems to achieve rapid actions on neuronal activity. Steroids and steroidal drugs interact directly with opioid receptors, including mu-opioid receptors, to alter binding affinities for endogenous opioids and subsequent neuronal activity (Maggi et al. 1996; SanMartin et al. 1999; Sajadi et al. 2007; Brown et al. 2008). A membrane glucocorticoid receptor recently isolated in newts exhibits kappa-opioid binding properties, and has been proposed to mediate the rapid actions of corticosterone on reproductive clasping behavior (Evans et al. 2000). In guinea pig hypothalamus, $\mathrm{E}_{2}$ rapidly inhibits the mu-opioid effector system (Kelly et al. 1992), although not via a direct interaction with opioid receptors per se (Qiu et al. 2003). In contrast, in rat hypothalamus, $\mathrm{E}_{2}$ causes mu-opioid receptor trafficking inward from the membrane (internalization) within $30 \mathrm{~min}$, and this effect can be blocked by treatment with the broad-spectrum opioid blocker naltrexone (Eckersell et al. 1998; Sinchak and Micevych 2001). Micevych and colleagues have proposed that $\mathrm{E}_{2}$ causes rapid release of opioid peptides, which then bind to mu-opioid receptors, leading to their internalization. The results of the current study are consistent with this model from rat hypothalamus, and support the hypothesis that the rapid effects of $E_{2}$ cause the release of mu-opioids within the VPG and thereby increase fictive call duration. This model for the midshipman VPG generates two specific predictions: (1) opioidergic modulatory neurons express estrogen-binding sites, most likely presynaptically within the VPG itself, and (2) estrogen treatment will lead to rapid increases in local mu-opioid concentrations accompanied by rapid internalization of mu-opioid receptors in the VPG region of midshipman.

This study demonstrates that steroids and neuropeptides can interact in the minute-by-minute control of motor network patterning, suggesting that acute shifts in midshipman calling behavior in nature involve combined rapid actions of estrogens and opioids (Fig. 1). Our findings are consistent with a mechanism of second-order, or "meta"-modulation, in which the actions of one neuromodulator (in this case $\mathrm{E}_{2}$ ) influence the actions of an existing neuromodulatory circuit (in this case mu-opioid neurons). Metamodulation provides an important mechanism for generating a broad range of behavioral states from a discrete network of neurons (Katz and Edwards 1999; Mesce 2002; McLean and Sillar 2004). Metamodulation is likely an important mechanism for shaping vocal output in midshipman, since the neuropeptides arginine vasotocin and isotocin also exert rapid actions on fictive calling in this species (Goodson and Bass 2000).

The current results suggest that the steroid-sensitive neural circuitry that patterns vocal production in other vertebrates (Schlinger and Brenowitz 2002; Bass and RemageHealey 2008; Jurgens 2008), could be regulated by acute steroid/opioid interactions similar to those in this study. Thus far, evidence has been suggestive in favor of this hypothesis. Masculinization of "crow" vocalizations in quail involves a testosterone-dependent upregulation of opioid binding sites in the brainstem (Bernroider et al. 1996). In addition, peripheral injections of opioid receptor antagonists increase male song production in starlings (Riters et al. 2005). However, to our knowledge neurophysiological evidence that opioids and steroids interact to regulate vocal patterning does not exist for birds and mammals. The mammalian hypothalamus exhibits sexually dimorphic expression of opioid peptides, and some neurons co-express mRNA for steroid receptors and opioids (Gu and Simerly 1994; Roepke et al. 2007). Therefore, rapid interactions between opioid- and steroid-dependent mechanisms, such as those outlined in this study, could be especially important for sex differences in brain function and behavioral plasticity in vertebrates.

Acknowledgments The authors thank Sue Moenter and Catherine Woolley for helpful suggestions about experimental treatments, and two anonymous referees for comments on the manuscript. All experimental protocols were approved by the Cornell University Institutional Animal Care and Use Committee. The research was supported by 
National Institutes of Health NINDS grants F32NS058009 and 1K99NS066179 (L.R.-H.), NIMH institutional predoctoral training grant 2T32MH015793 (L.R.-H.) and National Science Foundation grant IOB-0516748 (A.H.B.).

Open Access This article is distributed under the terms of the Creative Commons Attribution Noncommercial License which permits any noncommercial use, distribution, and reproduction in any medium, provided the original author(s) and source are credited.

\section{References}

Acosta-Martinez M, Etgen AM (2002) Activation of mu-opioid receptors inhibits lordosis behavior in estrogen and progesteroneprimed female rats. Horm Behav 41:88-100

Bass AH, Baker R (1990) Sexual dimorphisms in the vocal controlsystem of a teleost fish-morphology of physiologically identified neurons. J Neurobiol 21:1155-1168

Bass AH, McKibben JR (2003) Neural mechanisms and behaviors for acoustic communication in teleost fish. Prog Neurobiol 69:1-26

Bass AH, Remage-Healey L (2008) Central pattern generators for social vocalization: androgen-dependent neurophysiological mechanisms. Horm Behav 53:659-672

Bass AH, Marchaterre MA, Baker R (1994) Vocal-acoustic pathways in a teleost fish. J Neurosci 14:4025-4039

Bass AH, Gilland EH, Baker R (2008) Evolutionary origins for social vocalization in a vertebrate hindbrain-spinal compartment. Science 321:417-421

Behbehani MM (1995) Functional-characteristics of the midbrain periaqueductal gray. Prog Neurobiol 46:575-605

Bennett GJ, Mayer DJ (1979) Inhibition of spinal-cord interneurons by narcotic micro-injection and focal electrical-stimulation in the periaqueductal central gray-matter. Brain Res 172:243-257

Bernroider G, Holztrattner M, Rottner K (1996) Sex steroid-opioid interactions associated with the temporal component of avian calling patterns. Horm Behav 30:583-589

Bodnar RJ, Klein GE (2006) Endogenous opiates and behavior: 2005. Peptides 27:3391-3478

Bradford CS, Walthers EA, Searcy BT, Moore FL (2005) Cloning, heterologous expression and pharmacological characterization of a kappa opioid receptor from the brain of the rough-skinned newt, Taricha granulosa. J Mol Endocrinol 34:809-823

Brantley RK, Bass AH (1994) Alternative male spawning tactics and acoustic-signals in the plainfin midshipman fish Porichthys-notatus girard (teleostei, batrachoididae). Ethology 96:213-232

Brooks AI, Standifer KM, Cheng J, Ciszewska G, Pasternak GW (1994) Opioid binding in giant toad and goldfish brain. Receptor 4:55-62

Brown CH, Ludwig M, Leng G (1998) Kappa-opioid regulation of neuronal activity in the rat supraoptic nucleus in vivo. J Neurosci 18:9480-9488

Brown CH, Brunton PJ, Russell JA (2008) Rapid estradiol-17-beta modulation of opioid actions on the electrical and secretory activity of rat oxytocin neurons in vivo. Neurochem Res 33:614-623

Ceccarelli I, Fiorenzani P, Grasso G, Lariviere WR, Massafra C, Massai L, Muscettola M, Aloisi AM (2004) Estrogen and mu-opioid receptor antagonists counteract the 17 beta-estradiol-induced licking increase and interferon-gamma reduction occurring during the formalin test in male rats. Pain 111:181-190

Chaijale NN, Aloyo VJ, Simansky KJ (2008) A naloxonazine sensitive ([mu]1 receptor) mechanism in the parabrachial nucleus modulates eating. Brain Res 1240:111-118

Charpak S, Duboisdauphin M, Raggenbass M, Dreifuss JJ (1988) Direct inhibition by opioid-peptides of neurons located in the ventromedial nucleus of the guinea-pig hypothalamus. Brain Res 450:124-130

Cheng ZF, Fields HL, Heinricher MM (1986) Morphine microinjected into the periaqueductal gray has differential-effects on 3 classes of medullary neurons. Brain Res 375:57-65

Cornil CA, Ball GF, Balthazart J (2006a) Functional significance of the rapid regulation of brain estrogen action: where do the estrogens come from? Brain Res 1126:2-26

Cornil CA, Dalla C, Papadopoulou-Daifoti Z, Baillien M, Balthazart J (2006b) Estradiol rapidly activates male sexual behavior and affects brain monoamine levels in the quail brain. Behav Brain Res 166:110-123

Cross E, Roselli CE (1999) 17 Beta-estradiol rapidly facilitates chemoinvestigation and mounting in castrated male rats. Am J PhysiolReg I 276:R1346-R1350

Darlison MG, Greten FR, Harvey RJ, Kreienkamp HJ, Stuhmer T, Zwiers H, Lederis K, Richter D (1997) Opioid receptors from a lower vertebrate (Catostomus commersoni): sequence, pharmacology, coupling to a g-protein-gated inward-rectifying potassium channel (girk1), and evolution. Proc Natl Acad Sci USA 94:8214-8219

Deviche P, Cotter P, Gulledge CC (1993) Identification, partial characterization, and hypothalamic distribution of kappa-opioid, muopioid, and delta-opioid receptors in a passerine songbird (Junco hyemalis). Brain Res 614:220-226

Durand SE, Liang WR, Brauth SE (1998) Methionine enkephalin immunoreactivity in the brain of the budgerigar (Melopsittacus undulatus): similarities and differences with respect to oscine songbirds. J Comp Neurol 393:145-168

Ebbesson LOE, Deviche P, Ebbesson SOE (1996) Distribution and changes in mu- and kappa-opiate receptors during the midlife neurodevelopmental period of coho salmon, Oncorhynchus kisutch. J Comp Neurol 366:448-464

Eckersell CB, Popper P, Micevych PE (1998) Estrogen-induced alteration of mu-opioid receptor immunoreactivity in the medial preoptic nucleus and medial amygdala. J Neurosci 18:3967-3976

Evans SJ, Searcy BT, Moore FL (2000) A subset of kappa opioid ligands bind to the membrane glucocorticoid receptor in an amphibian brain. Endocrinology 141:2294-2300

Flores CA, Shughrue P, Petersen SL, Mokha SS (2003) Sex-related differences in the distribution of opioid receptor-like 1 receptor mRNA and colocalization with estrogen receptor mRNA in neurons of the spinal trigeminal nucleus caudalis in the rat. Neuroscience 118:769-778

Forlano PM, Deitcher DL, Myers DA, Bass AH (2001) Anatomical distribution and cellular basis for high levels of aromatase activity in the brain of teleost fish: aromatase enzyme and mRNA expression identify glia as source. J Neurosci 21:8943-8955

Gogas KR, Levine JD, Basbaum AI (1996) Differential contribution of descending controls to the antinociceptive actions of kappa and mu opioids: an analysis of formalin-evoked c-fos expression. J Pharmacol Exp Ther 276:801-809

Goodson JL, Bass AH (2000) Forebrain peptides modulate sexually polymorphic vocal circuitry. Nature 403:769-772

Goodson JL, Bass AH (2002) Vocal-acoustic circuitry and descending vocal pathways in teleost fish: convergence with terrestrial vertebrates reveals conserved traits. J Comp Neurol 448:298-322

Gu GB, Simerly RB (1994) Hormonal-regulation of opioid peptide neurons in the anteroventral periventricular nucleus. Horm Behav 28:503-511

Gutierrez M, Menendez L, Brieva R, Hidalgo A, Baamonde A (1998) Different types of steroids inhibit [h-3]diprenorphine binding in mouse brain membranes. Gen Pharmacol 31:747-751

Heinricher MM (2003) Orphanin fq/nociceptin: from neural circuitry to behavior. Life Sci 73:813-822 
Jurgens U (2008) The neural control of vocalization in mammals: a review. J Voice 23(1):1-10

Katz PS, Edwards DH (1999) Metamodulation: the control and modulation of neuromodulation. In: Katz PS (ed) Beyond neurotransmission: neuromodulation and its importance for information processing. Oxford University Press, New York, pp 349-381

Kelly MJ, Ronnekleiv OK (2002) Rapid membrane effects of estrogen in the central nervous system. In Pfaff D (ed) Hormones, brain and behavior. Elsevier, pp 361-380

Kelly MJ, Loose MD, Ronnekleiv OK (1992) Estrogen suppresses muopioid-mediated and GABA(b)-mediated hyperpolarization of hypothalamic arcuate neurons. J Neurosci 12:2745-2750

Khalap A, Bagrosky B, Le Caude S, Youson J, Danielson P, Dores RM (2005) Trends in the evolution of the proenkephalin and prodynorphin genes in gnathostomes. Trends Comp Endocrinol Neurobiol 1040:22-37

Kittelberger JM, Land BR, Bass AH (2006) The midbrain periaqueductal gray and vocal patterning in a teleost fish. J Neurophysiol 96:71-85

Lagrange AH, Ronnekleiv OK, Kelly MJ (1997) Modulation of g protein-coupled receptors by an estrogen receptor that activates protein kinase a. Mol Pharmacol 51:605-612

Li X, Keith DE, Evans CJ (1996) Mu opioid receptor-like sequences are present throughout vertebrate evolution. J Mol Evol 43:179184

Maggi R, Pimpinelli F, Casulari LA, Piva F, Martini L (1996) Antiprogestins inhibit the binding of opioids to mu-opioid receptors in nervous membrane preparations. Eur J Pharmacol 301:169-177

Martin TJ, McIntosh S, Smith JE (2006) Alkylation of opioid receptors by $5^{\prime}$-naltrindole-isothiocyanate injected into the nucleus accumbens of rats: receptor selectivity and anatomical diffusion. Synapse 60:384-391

McLean DL, Sillar KT (2004) Metamodulation of a spinal locomotor network by nitric oxide. J Neurosci 24:9561-9571

Menuet A, Pellegrini E, Brion F, Gueguen MM, Anglade I, Pakdel F, Kah O (2005) Expression and estrogen-dependent regulation of the zebrafish brain aromatase gene. J Comp Neurol 485:304-320

Mesce KA (2002) Metamodulation of the biogenic amines: second-order modulation by steroid hormones and amine cocktails. Brain Behav Evol 60:339-349

Mitchell JM, Liang MT, Fields HL (2005) A single injection of the kappa opioid antagonist norbinaltorphimine increases ethanol consumption in rats. Psychopharmacology (Berl) 182:384-392

Nugent FS, Penick EC, Kauer JA (2007) Opioids block long-term potentiation of inhibitory synapses. Nature 446:1086-1090

Pascoe JE, Williams KL, Mukhopadhyay P, Rice KC, Woods JH, Ko M-C (2008) Effects of mu, kappa, and delta opioid receptor agonists on the function of hypothalamic-pituitary-adrenal axis in monkeys. Psychoneuroendocrinology 33:478-486

Pinto PIS, Passos AL, Martins RS, Power DM, Canario AVM (2006a) Characterization of estrogen receptor beta $\mathrm{b}$ in sea bream (Sparus auratus): phylogeny, ligand-binding, and comparative analysis of expression. Gen Comp Endocrinol 145:197-207

Pinto PIS, Singh PB, Condeca JB, Teodosio HR, Power DM, Canario AVM (2006b) ICI 182, 780 has agonistic effects and synergizes with estradiol-17 beta in fish liver, but not in testis. Reprod Biol Endocrinol 4:67-78

Porteros A, Garcia-Isidoro M, Barrallo A, Gonzalez-Sarmiento R, Rodriguez RE (1999) Expression of zfor1, a delta-opioid receptor, in the central nervous system of the zebrafish (Danio rerio). J Comp Neurol 412:429-438

Qiu J, Bosch MA, Tobias SC, Grandy DK, Scanlan TS, Ronnekleiv OK, Kelly MJ (2003) Rapid signaling of estrogen in hypothalamic neurons involves a novel g-protein-coupled estrogen receptor that activates protein kinase c. J Neurosci 23:9529-9540

Remage-Healey L, Bass AH (2004) Rapid, hierarchical modulation of vocal patterning by steroid hormones. J Neurosci 24:5892-5900

Remage-Healey L, Bass AH (2005) Rapid elevations in both steroid hormones and vocal signaling during playback challenge: a field experiment in gulf toadfish. Horm Behav 47:297-305

Remage-Healey L, Bass AH (2006) From social behavior to neural circuitry: steroid hormones rapidly modulate advertisement calling via a vocal pattern generator. Horm Behav 50:432-441

Remage-Healey L, Bass AH (2007) Plasticity in brain sexuality is revealed by the rapid actions of steroid hormones. J Neurosci 27:1114-1122

Riters LV, Schroeder MB, Auger CJ, Eens M, Pinxten R, Ball GF (2005) Evidence for opioid involvement in the regulation of song production in male European starlings (Sturnus vulgaris). Behav Neurosci 119:245-255

Roepke TA, Malyala A, Bosch MA, Kelly MJ, Ronnekleiv OK (2007) Estrogen regulation of genes important for $\mathrm{K}+$ channel signaling in the arcuate nucleus. Endocrinology 148:4937-4951

Sajadi AA, Samaei SA, Rashidy-Pour A (2007) Blocking effects of intra-hippocampal naltrexone microinjections on glucocorticoidinduced impairment of spatial memory retrieval in rats. Neuropharmacology 52:347-354

SanMartin S, Gutierrez M, Menendez L, Hidalgo A, Baamonde A (1999) Effects of diethylstilbestrol on mouse hippocampal evoked potentials in vitro. Cell Mol Neurobiol 19:691-703

Schlinger B, Brenowitz EA (2002) Neural and hormonal control of birdsong. In: Pfaff DW (ed) Hormones, brain and behavior. Elsevier, pp 799-838

Schmitt PM, Kaufman MP (2005) Estrogen's attenuating effect on the exercise pressor reflex is more opioid dependent in gonadally intact than in ovariectomized female. J Appl Physiol 98:633-639

Sinchak K, Micevych PE (2001) Progesterone blockade of estrogen activation of mu-opioid receptors regulates reproductive behavior. J Neurosci 21:5723-5729

Sisneros JA, Forlano PM, Knapp R, Bass AH (2004) Seasonal variation of steroid hormone levels in an intertidal-nesting fish, the vocal plainfin midshipman. Gen Comp Endocrinol 136:101-116

Tashiro A, Okamoto K, Bereiter DA (2008) Morphine modulation of temporomandibular joint-responsive units in superficial laminae at the spinomedullary junction in female rats depends on estrogen status. Eur J Neurosci 28:2065-2074

Torres-Reveron A, Williams TJ, Chapleau JD, Waters EM, McEwen BS, Drake CT, Milner TA (2009) Ovarian steroids alter mu opioid receptor trafficking in hippocampal parvalbumin gabaergic interneurons. Exp Neurol 219:319-327

Vasudevan N, Kow LM, Pfaff D (2005) Integration of steroid hormone initiated membrane action to genomic function in the brain. Steroids 70:388-396

Weeg MS, Land BR, Bass AH (2005) Vocal pathways modulate efferent neurons to the inner ear and lateral line. J Neurosci 25:59675974

Woolley CS (2007) Acute effects of estrogen on neuronal physiology. Annu Rev Pharmacol 47:657-680 